\title{
Tension wood and growth stress induced by artificial inclination in Liriodendron tulipifera Linn. and Prunus spachiana Kitamura f. ascendens Kitamura
}

\author{
Masato Yoshida*, Tomonobu Okuda and Takashi Okuyama \\ Laboratory of Bio-Material Physics, Graduate School of Bioagricultural Sciences, Nagoya University, Nagoya 464-8601, Japan
}

(Received 19 July 1999; accepted 28 February 2000)

\begin{abstract}
The relationship between the amount of growth stress and the degree of artificial inclination was investigated in saplings of two angiosperm species. The tensile growth stresses generated in Prunus spachiana, which forms gelatinous fibers, were larger than those in Liriodendron tulipifera, which does not form gelatinous fibers. In both species, the tensile growth stresses generated in the upper side of inclined stems increased and the cellulose microfibrillar angle decreased proportionally as the inclination changed from $0^{\circ}$ (vertical) to $20^{\circ}$. At inclinations over $20^{\circ}$, the tensile growth stress and cellulose microfibrillar angle did not change further. The thickness of the current growth layer increased linearly with the angle of inclination, but eccentric growth was not the main factor contributing to the upward bending moment to return the axis to the normal vertical position. This paper reveals that the growth stress generated by inclination is limited. That is, growth stress increases with the inclination angle to a point, but then does not
\end{abstract} increase further.

artificial inclination / tensile growth stress / tension wood / Prunus spachiana Kitamura f. ascendens Kitamura / Liriodendron tulipifera Linn.

Résumé - Bois de tension et contrainte de croissance induits par inclinaison artificielle chez Liriodendron tulipifera Linn. et Prunus spachiana Kitamura f. ascendens Kitamura. La relation entre la contrainte de croissance et le niveau d'inclinaison artificielle a été étudiée sur des pousses de deux espèces angiospermes. La contrainte de croissance de traction générée par Prunus spachiana, qui produit des fibres gélatineuses, est plus forte que celle de Liriodendron tulipifera, qui n'en produit pas. Dans les deux espèces, une augmentation de l'inclinaison de 0 à $20^{\circ}$ par rapport à la verticale, produit proportionnellement une augmentation de la contrainte de traction générée sur la face supérieure de la tige inclinée et une décroissance de l'angle des microfibrilles cellulosiques. Des inclinaisons supérieures à $20^{\circ}$ ne produisent pas de variation supplémentaire, ni de la contrainte ni de l'angle des microfibrilles. La largeur du cerne en cours de formation augmente linéairement avec l'angle d'inclinaison, toutefois l'excentricité de la croissance n'est pas un facteur contribuant de manière dominante au moment de flexion induisant le retour à la position verticale normale. Cet article révèle le caractère borné de la contrainte de croissance, qui peut augmenter jusqu'à un certain point mais ensuite ne dépasse pas cette limite.

inclinaison artificielle / contrainte de croissance / bois de tension / Prunus spachiana Kitamura f. ascendens Kitamura / Liriodendron tulipifera Linn.

* Correspondence and reprints

Tel. (81) 52789 4153; Fax. (81) 52789 4150; e-mail: yoshida@agr.nagoya-u.ac.jp 


\section{INTRODUCTION}

Reaction wood is wood with distinctive anatomical characteristics, and typically forms in leaning or crooked trunks and branches; it tends to restore the limb or trunk to its original position $[5,6]$ by increasing growth stress.

Tension wood is reaction wood that typically forms in the upper sides of branches and leaning trunks of dicotyledonous trees, and it is characterized anatomically by the presence of gelatinous fibers that contain a conspicuously thickened gelatinous layer. In tension wood, the tensile growth stress increases with the number of gelatinous fibers, increasing cellulose content, and decreasing microfibrillar angle $[8,10]$. In dicotyledonous trees that lack definite gelatinous fibers, the tensile growth stress increases with cellulose content and decreasing microfibrillar angle and lignin content $[8$, 10]. In trees where the reaction wood is not characterized anatomically, growth stress is used to determine the intensity of the reaction wood $[1,2]$.

If the purpose of developing reaction wood and generating larger growth stress is to return a leaning tree to the upright position, then the intensity of reaction wood and the cambial growth speed should increase with the inclination of the trunk. However, growth stresses measured in leaning trunks do not increase with the inclination from the vertical [11]. We found that the growth stress generated in an inclined trunk was larger than in a vertical one, but the growth stress in a trunk leaning at an extreme angle (over $45^{\circ}$ ) was often smaller than that in a trunk at $20^{\circ}$. This suggests that growth stress increases with the angle of the trunk to a certain point, but then remains constant or decreases. If the growth stress does not increase in a severely tilted stem, accelerated thickening growth will induce sufficient upward moment to return the axis of the trunk to the vertical. If the growth stress decreases, a lateral shoot will be converted into the main shoot.

To test this hypothesis, we investigated the relationship between the growth stress and the angle of inclination of the stems of saplings of two angiosperm species. One species forms gelatinous fibers and the other does not.

\section{MATERIALS AND METHODS}

Experiments were conducted from April 1997 to February 1998 in a field owned by Nagoya University, Japan. Cloned three-year-old saplings of Prunus spachiana Kitamura f. ascendens Kitamura, which forms gelatinous fibers, and Liriodendron tulipifera Linn., which does not [9], were planted in pots (height $30 \mathrm{~cm}$, diameter $20 \mathrm{~cm}$, filled with a mixture of red soil and

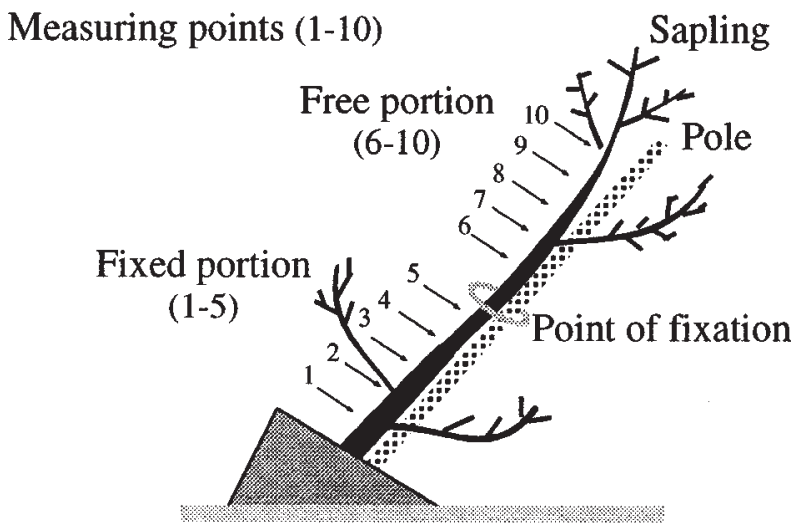

Figure 1. Experimental setup. A pole attached to the stem of the sapling $50 \mathrm{~cm}$ above the ground maintained the inclination of the lower part of the stem. Above the point of fixation, the stem was free to return to its original position.

compost). The saplings were watered every 3 days. No fertilizers were used during the experimental period. Fifteen normal saplings each of Prunus spachiana (avg. height $150 \mathrm{~cm}$ ) and Liriodendron tulipifera (avg. height $140 \mathrm{~cm}$ ) were chosen and artificially inclined to the south. Three saplings of each species were inclined at angles of $0^{\circ}, 10^{\circ}, 20^{\circ}, 40^{\circ}$, and $60^{\circ}$ from the vertical at the beginning of the initiation of cambial growth in early spring. To avoid any mechanical disturbance, the position of each sapling was maintained by a pole attached to the stem $50 \mathrm{~cm}$ above the ground. This prevented the stem between the base and the point of fixation from returning to the vertical (figure 1). The pots were arranged in a randomized block design. Eight months later, in the dormant season, after a full season's growth, the stems above the point of fixation in the inclined saplings bent upward. Tissue observations were made and the released strain induced by growth stress and the mean microfibrillar angle, which contributes to growth stress [8], were measured.

\subsection{Released strain of growth stress}

The saplings were fixed to a pole to prevent them from returning to the vertical. Initial measurements were made with the sapling fixed to the pole. When the fixation was released in the dormant season, the saplings sprang upward. This is known as the "spring-back" phenomenon, and is induced by the release of the growth stress that has built up during the growing season.

The longitudinal growth stress at the outer surface of the secondary xylem was measured by releasing the 
stress, as previously described [16]. The longitudinal released strain was measured with strain gauges at 10 points on the upper side of the leaning stem, five between the base and the point of fixation and five above this point (figure 1). At each point, the smooth outer surface of the secondary xylem was exposed by removing the bark, cambial zone, and differentiating xylem with a knife, so as not to scratch the xylem surface. A 2-mm long strain gauge (Minebea, B-FAE-2S-12-T11) was glued to the xylem surface lengthwise with CY-10 adhesive (Minebea), and connected to a strain meter (Kyowa, UCAM-1A) in 1 gauge- 3 wire mode. The measurement precision was $\pm 0.001 \%$. After the initial measurements had been made in the fixed sapling, a groove was cut to the depth of the current growth layer (2-3 $\mathrm{mm})$ close to each side of the strain gauge to release the growth stress. The distance from the edge of the gauge to the groove was $2 \mathrm{~mm}$. The strain measured is the strain released from the growth stress and is proportional to the growth stress. Compressive growth stress induces swelling between the grooves, and the longitudinal released strain is deemed positive. Tensile growth stress induces shrinkage between the grooves and the released strain is negative.

\subsection{Tissue observation}

Field emission scanning electron microscopy (FESEM) and light microscopy were used for tissue observation. Small blocks of tissue containing the strain gauge and the xylem were cut from the measuring points after measuring the released strain. The samples were fixed with $3 \%$ glutaraldehyde overnight at $4{ }^{\circ} \mathrm{C}$ and sectioned radially into approximately $50 \mu \mathrm{m}$ thick sections using a freezing-sliding microtome at $-20{ }^{\circ} \mathrm{C}$. After washing with distilled water, the sections were fixed in $1 \%$ osmium tetroxide for 24 hours at room temperature, and then washed with distilled water three times, for 60 minutes each time. The sections were dehydrated through a graded ethanol series and then processed using the t-butyl alcohol freeze-drying method. The dried sections were mounted on aluminum stubs and lightly sputter-coated with platinum and palladium. The inner surface of the radial wall of mature fibers was observed by FE-SEM (Hitachi, S-4500) at an accelerating voltage of $3 \mathrm{kV}$.

Cross-sections, $15 \mu \mathrm{m}$ thick, were prepared from the block samples for light microscopic observation, and stained with safranine (4\% in $50 \%$ ethanol) for 3 hours. Then, the sections were stained with fast green $(0.5 \%$ in $95 \%$ ethanol) for 5 minutes and dehydrated through a graded ethanol series. After double staining and dehydration, the sections were mounted on a clean glass slide

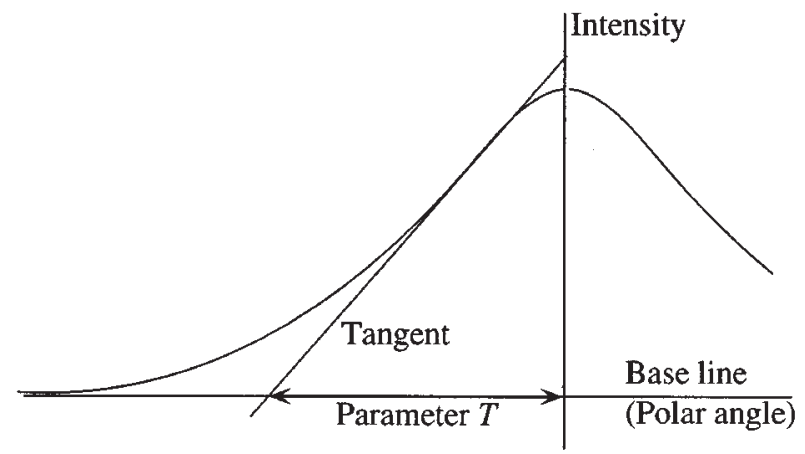

Figure 2. Measuring parameter $T$ from a (200) X-ray diffractogram reflection.

with Entellan (Merck, Germany) and observed with a light microscope (Zeiss, Axiophot-2).

\subsection{Microfibrillar angle}

An X-ray diffractometer (Shimazu, XD-D1) was used to determine the average microfibrillar angle [3, 7, 15]. A point-focused $\mathrm{X}$-ray beam $(\mathrm{Cu}-\mathrm{Ka} \mathrm{X}$-ray, beam diameter $1 \mathrm{~mm}$ ) was applied to tangential sections, $200 \mu \mathrm{m}$ thick $\times 15 \mathrm{~mm}$ long, prepared from the current growth layer with a sliding microtome. An X-ray diffraction apparatus with a symmetrical transmission mode was used. The measurements were made at a speed of 6 degrees per minute in sample holder rotation, at a Bragg's angle of $22.4^{\circ}$, using a 2-mm divergence slit and a 1-mm receiving slit. Parameter $T$ defined by Cave [3] was obtained from the diffraction intensity around (200) arc. Three lines were drawn to derive half the width of the curve. The first was the baseline representing the portion in the curve where the X-ray intensity was more or less minimal. Then, a tangent was drawn through the inflection point on one side of the curve. Finally, a vertical line was drawn to divide the curve into two equal parts (figure 2). The average microfibrillar angle (MFA) was calculated using the formula [15]:

$M F A=1.575 \times 10^{-3} T^{3}-1.431 \times 10^{-1} T^{2}+4.693 T-36.19$.

\subsection{Upward moment}

The difference in growth stress between tension wood (upper side) and normal wood (lower side) generates an internal bending moment that tends to bend the stem back towards the vertical, in a righting response. Therefore, the moment in an upright sapling is zero. To simplify the estimate of the moment in this study, it was 
assumed that growth stresses were not generated in the opposite side. The upward bending moment in the sapling was estimated by subtracting the moment in the upright sapling from the moment in each sapling. The upward bending moment $(M)$ to return the stem axis to the vertical was computed from the released strain of the growth stress $(\varepsilon)$ generated in the upper side of the inclined stem and the area of the tension wood region in the current growth layer $(A)$, using the formula:

$$
M=\varepsilon E \int_{A} y \mathrm{~d} A
$$

where $E$ is the longitudinal Young's modulus of the stem, and $y$ is the distance from the neutral axis. Parameters $A$ and $y$ were measured in the sample used for tissue observation. It was assumed that Young's modulus was unique in the stem and that growth stress was generated only in the tension wood region of the current growth layer of the stem.
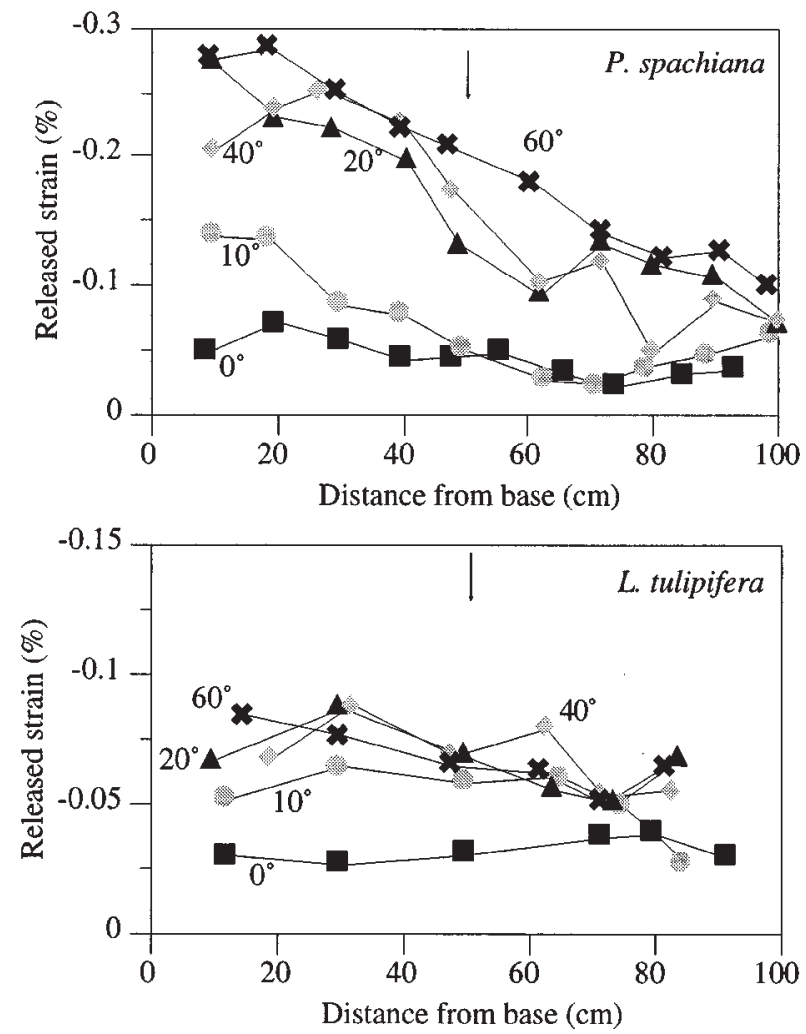

Figure 3. Released strain of growth stress in the upper side of the stem. The numbers indicate the angle of inclination from the vertical. Each point is the average for 3 saplings. The mean standard deviation of each point is 0.06 in P. spachiana and 0.02 in L. tulipifera. The arrow indicates the point of fixation.

\section{RESULTS}

\subsection{Longitudinal released strain of growth stress}

The negative released strain, which represents tensile growth stress, was measured on the upper side of the stem in all the saplings. Statistical analyses showed that differences between saplings inclined at the same angle were not significant. In upright saplings, the negative released strain was virtually constant along the stem, while in inclined saplings the strain was largest at the base and decreased toward the tip (figure 3). The released strain at the base tended to increase with the angle of inclination from the vertical, while the released strain at the tip remained almost the same, irrespective of the angle. The released strain did not change markedly at the fixation point.

At the same angle of inclination (figure 3), the tensile released strain was larger in Prunus spachiana than in
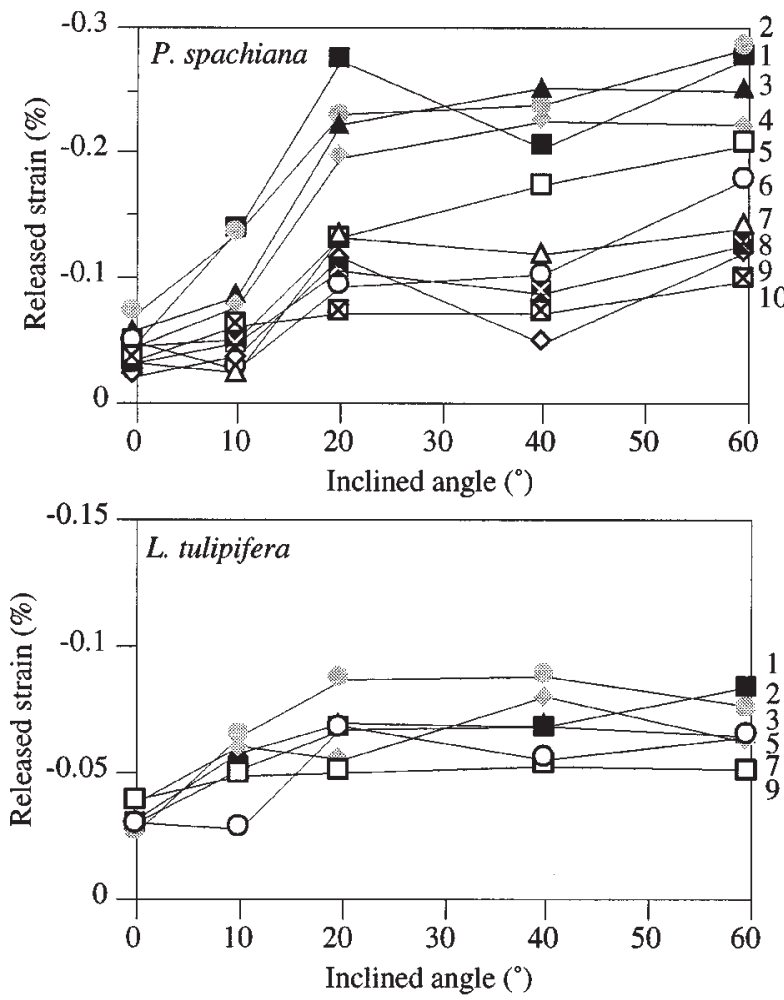

Figure 4. Change in the released strain on the upper side of the stem with the angle of inclination. The numbers on the right of the figure indicate the position on the stem from the base to the top. Each point is the average for 3 saplings. The mean standard deviation of each point is 0.06 in P. spachiana and 0.02 in L. tulipifera. 
Liriodendron tulipifera. At the base, where the largest released strains were measured, there was a 5-fold increase in the released strain from an angle of $0^{\circ}$ to $60^{\circ}$ in Prunus spachiana and a 3 -fold increase in Liriodendron tulipifera.

The released strain increased with the angle of inclination up to an angle of $20^{\circ}$, and then remained constant (figure 4). This trend was observed at all measuring points. Up to $20^{\circ}$ inclination, the increase in the released strain was greatest near the base of the sapling.

\subsection{Microfibrillar angle}

Field emission scanning electron microscopy was used to observe the innermost surface of the radial wall in mature fibers in the upper side of the saplings. In Prunus spachiana, the cellulose microfibrils deposited on the inner surface of tension wood fibers paralleled the fiber axis in all leaning saplings, regardless of the angle of
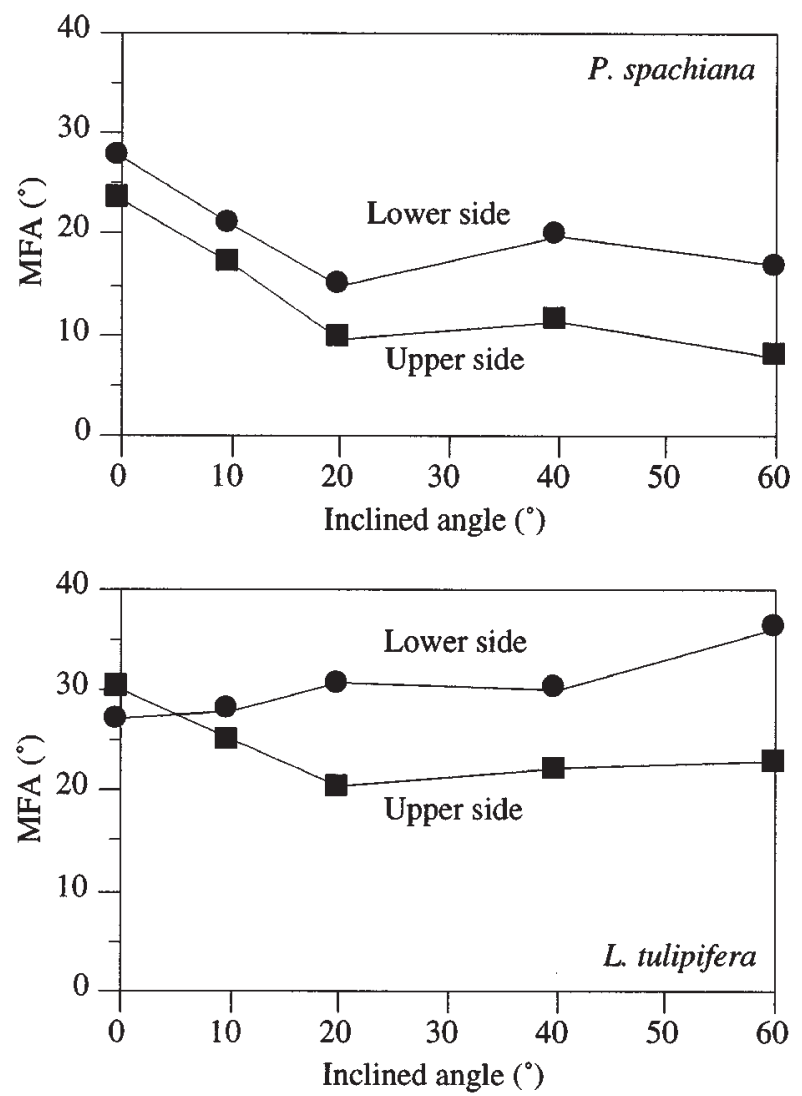

Figure 5. Change in microfibrillar angle with the angle of inclination. Each point is the average for 3 saplings. The mean standard deviation of each point is 4 in $P$. spachiana and 3 in L. tulipifera. inclination. In the upright saplings, the microfibrils were oriented at an angle of about $20^{\circ}$ to the fiber axis in a Z-helix. In Liriodendron tulipifera, the microfibrils were oriented at an angle of about $20^{\circ}$ to the fiber axis in a Z-helix in all the inclined stems, and at an angle of about $30^{\circ}$ to the fiber axis in a Z-helix in the upright saplings.

Figure 5 shows the mean microfibrillar angle (MFA) determined using an X-ray diffractometer. In the upper side of the stem, the MFA decreased in both species as the angle of inclination increased up to $20^{\circ}$, and then remained constant. In the lower side, the MFA decreased with the angle of inclination in Prunus spachiana, but did not change with the angle of inclination in Liriodendron tulipifera.

\subsection{Tissue observation}

The thickness of the current growth layer increased linearly in the upper side and decreased linearly in the
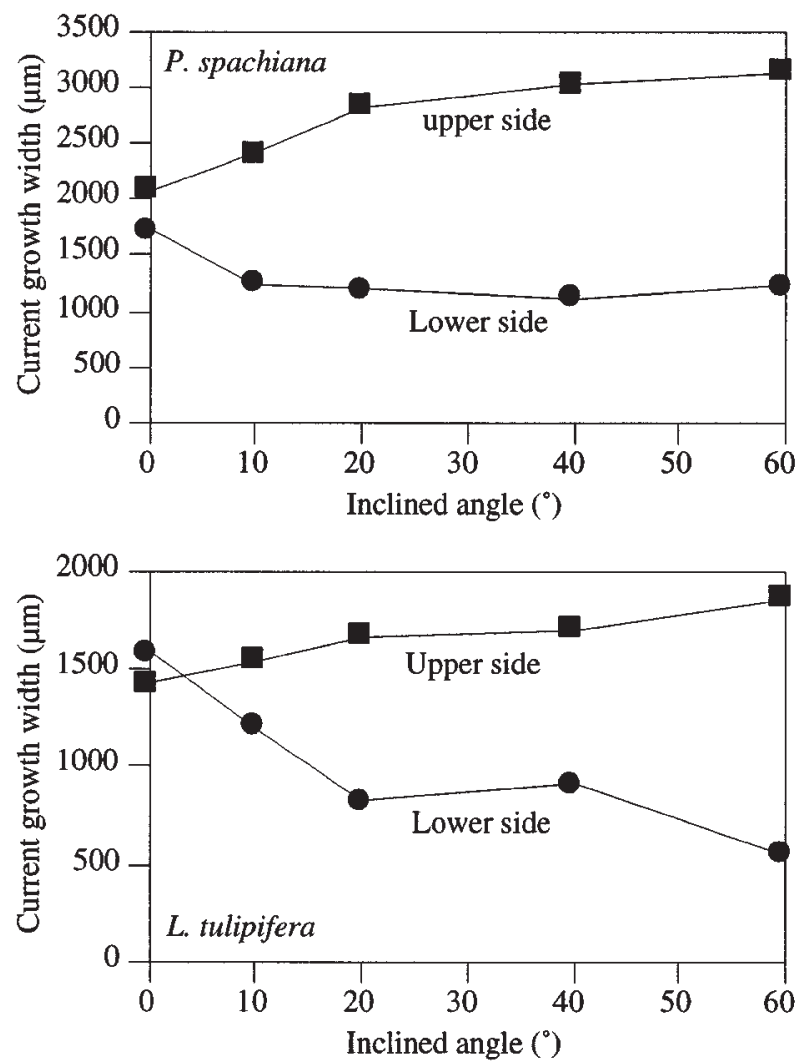

Figure 6. Change in the width of the current growth layer with the angle of inclination. Each point is the average for 3 saplings. The mean standard deviation of each point is 380 in P. spachiana and 300 in L. tulipifera. 

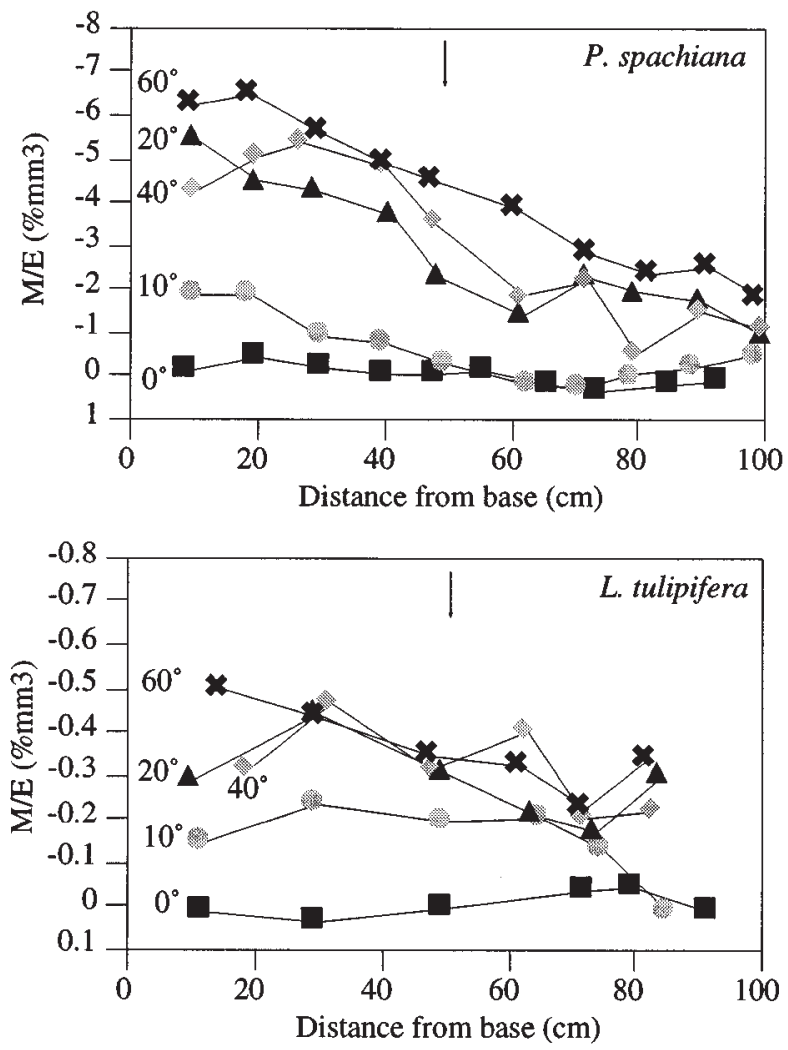

Figure 7. Upward moment resulting from growth stress along the stem. The numbers in the figure indicate the angle of inclination from the vertical. A negative value in the vertical axis indicates the upward moment. The arrow indicates the point of fixation.

lower side in proportion to the increase in the angle of inclination (figure 6).

In the current growth layer of the inclined saplings, tension wood was present only in the upper side, both below and above the point of fixation, and was produced continuously. The upright saplings did not produce tension wood in the current growth layer.

\subsection{Upward moment}

The distribution of the upward moment (negative value) in saplings, calculated from the released strain and the area of tension wood, was similar to that of the released strain of growth stress (figure 7). The value was constant along the stem in upright saplings. In inclined saplings, the value was largest at the base and decreased toward the tip. The moment at the base
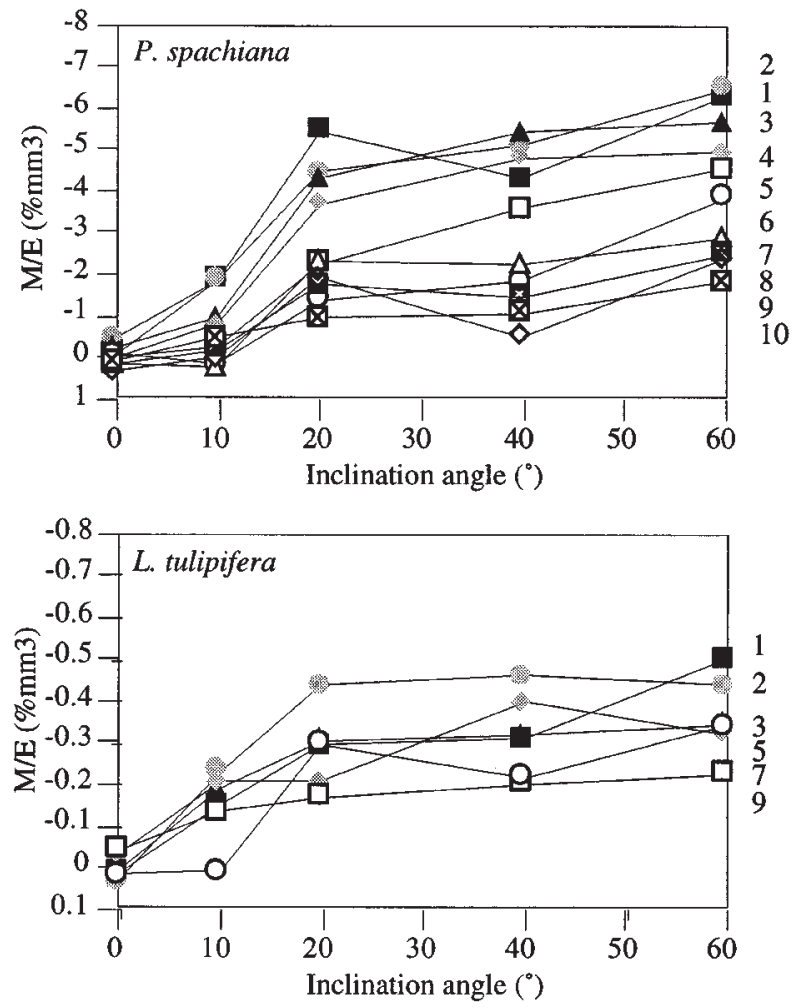

Figure 8. Change in the upward moment resulting from growth stress with the angle of inclination. The numbers on the right side of the figure indicate the position on the stem from the base to the top.

tended to increase with the angle of inclination, while the moment near the tip remained essentially constant, regardless of the angle of inclination. The moment did not change markedly at the point of fixation.

At all measuring points, the upward moment increased with the saplings' angle of inclination until $20^{\circ}$ from vertical, and then tended to remain constant (figure 8).

\section{DISCUSSION}

A leaning stem acts like a tapered cantilever. The downward moment of the plant's weight is largest at the base of the stem and decreases toward the tip. In this study, the position and orientation of each sapling was maintained by a pole to avoid any mechanical disturbance and to prevent the righting movement. Thus, the downward moment was largest at the point of fixation and was almost zero below this point. If tension wood 
and larger growth stresses were formed to counter the downward moment due to weight, they would not exist in the basal part. However, the released strain was greatest in the basal part, and the results therefore show that the saplings' response was linked to inclination and not to gravitational moment. In an inclined stem, the distribution of the negative released strain in the upper side tends to counter the inclination and return the stem's axis to the vertical. The tensile growth stress generated in the upper side of the stem bends the part of the stem above the point of fixation upward (figure 1), as this part is free to return to the vertical. This return starts from the tip, where the diameter is smallest and the stem is most readily bent by the moment. Once the stem's orientation is restored, large growth stresses are not required; the released strains measured at the tips of the stems were almost the same, regardless of the angle of inclination (figure 3).

The released strain of the growth stress generated in the upper side of the inclined stems increased with inclination from $0^{\circ}$ to $20^{\circ}$. At inclinations over $20^{\circ}$, the released strain did not increase further. Wilson and Gartner [11] reported that in naturally leaning red alder, the lean angle is positively correlated with differential growth stress between the upper and lower sides in trees without tension wood, but not in trees with tension wood. Their results in mature natural trees and our results with the experimental saplings agree that growth stress generated by inclination is limited.

Prunus spachiana forms gelatinous fibers in the tension-wood region, while Liriodendron tulipifera does not. In Liriodendron tulipifera, the cellulose content increases and the MFA parallels the fiber axis in the tension wood region in the upper side of an inclined stem $[10,13]$. These changes generate a larger tensile growth stress [14]. Gelatinous fibers appear to be the product of increased cellulose and microfibrils that parallel the fiber axis. We found that Prunus spachiana, which forms gelatinous fibers, generated more tensile growth stress than Liriodendron tulipifera, which does not. This implies that the gelatinous layer generates more tensile growth stress. Experiments should be conducted on other species to confirm this.

In Prunus spachiana, the MFA measured by X-ray diffractometer was larger than the microfibrillar orientation on the innermost surface of mature fibers, while in Liriodendron tulipifera the MFA corresponded to the microfibrillar orientation (figure 5). The difference in Prunus spachiana is probably due to the presence of the gelatinous layer. X-ray diffraction measures the mean microfibrillar angle of the cell wall including the gelatinous layer and other layers, whereas FE-SEM observes only the surface of the innermost gelatinous layer, so that the orientation of the gelatinous layer is measured.

The change in MFA is similar to the change in the released strain of growth stress in the upper side of the stem. In saplings, MFA decreases with the inclination of the stem up to $20^{\circ}$, and then remains constant. This agrees with the relationship between tensile growth stress and MFA reported previously [13].

When a tree grows eccentrically and produces reaction wood, thickening is promoted on the reaction-wood side, and inhibited on the opposite side [4]. The decrease in the thickness of the current growth layer in the lower side with increasing inclination (figure 6) results from the production of tension wood in the upper side of the leaning stem. In a naturally leaning tree, tension wood is present in one ring, missing in the next one or more rings, and then present again; and reverses on the lower side so that there is a band comprised of both normal wood and tension wood [11]. In the saplings used in this study, the righting movement was inhibited below the point of fixation; thus in the current growth layer tension wood was produced continuously in the upper side and did not reverse on the lower side.

The degree to which a segment of a leaning stem bends upward to counteract the lean depends on the upward moment due to growth stress, and the area and position of the reaction wood region. With large growth stress and a small area of reaction wood, the stem axis will not readily return to the vertical position. With identical growth stress, it is the tree with the larger area of reaction wood that will return to the vertical more readily. The increased thickness of the current growth layer in a leaning stem seems to increase the upward moment, but the calculated moment did not increase linearly with the angle of inclination (figure 8).

In this study, Young's modulus was assumed to be constant along the stem at any inclination, as it was difficult to estimate Young's modulus in the current year's growth layer. The Young's modulus of the cell wall is strongly dependent on the microfibrillar angle; a reduction increases Young's modulus $[12,13]$. The moment seems to increase from $0^{\circ}$ to $20^{\circ}$ inclination and then to remain constant. The critical angle might change if we were to measure Young's modulus in the current layer. The distribution of the upward moment was the same as that of the released strain, and increased thickening did not appear to play a dominant role in increasing the upward moment. Generating a larger growth stress was more important for returning a leaning stem to vertical than eccentric growth.

In conclusion, we described the relationship between the tensile growth stress generated by artificial 
inclination and the degree of inclination in saplings of two angiosperm species. Tensile growth stresses in the upper side of the stem increased with the angle of inclination up to a point, but then did not increase with further inclination. In the saplings studied, the critical angle of inclination was about $20^{\circ}$ from the vertical. Inclination stimulates thickened growth, but growth stress is the main factor in returning the stem axis to the vertical.

Acknowledgments: We thank Dr Joseph Gril (Université Montpellier 2) for translating the abstract into French.

\section{REFERENCES}

[1] Baillères H., Chanson B., Fournier M., Tollier M.T., Monties B., Structure, composition chimique et retraits de maturation du bois chez les clones d'Eucalyptus, Ann. Sci. For. 52 (1995) 157-172.

[2] Baillères H., Castan M., Monties B., Pollet B., Lapierre C., Lignin structure in Buxus sempervirens reaction wood, Phytochemistry 44 (1997) 35-39.

[3] Cave I.D., Theory of X-ray measurement of microfibril angle, Forest Prod. J. 16 (1966) 37-42.

[4] Côté W.A., Day A.C., Anatomy and ultrastructure of reaction wood, in: Côté W.A. (Ed.), Cellular ultrastructure of woody plants, Syracuse University Press, Syracuse, 1965, pp. 391-418.

[5] Ford-Robertson F.C., Terminology of forest science, technology practice and products, Society of American Foresters, Washington D.C., 1971.

[6] IAWA Committee, Multilingual glossary of terms used in wood anatomy, Zürich, 1964.
[7] Meylan B.A., Measurement of microfibril angle by Xray diffraction, Forest Prod. J. 17 (1967) 51-58.

[8] Okuyama T., Yamamoto H., Yoshida M., Hattori Y., Archer R.R., Growth stresses in tension wood: Role of microfibrils and lignification, Ann. Sci. For. 51 (1994) 291-300.

[9] Onaka F., Studies on compression- and tension-wood, Mokuzai Kenkyu 1 (1949) 1-88.

[10] Sugiyama K., Okuyama T., Yamamoto H., Yoshida M., Generation process of growth stress in cell walls: Relation between longitudinal released strain and chemical composition, Wood Sci. Technol. 27 (1993) 257-262.

[11] Wilson B. F., Gartner B. L., Lean in red alder (Alnus rubra): growth stress, tension wood, and righting response, Can. J. For. Res. 26 (1996) 1951-1956.

[12] Yamamoto H., Okuyama T., Yoshida M., Sugiyama K., Generation process of growth stress in cell walls III: Growth stress in compression wood, Mokuzai Gakkaishi 37 (1991) 94-100.

[13] Yamamoto H., Okuyama T., Sugiyama K., Yoshida M., Generation process of growth stresses in cell walls IV: Action of the cellulose microfibril upon the generation of the tensile stresses, Mokuzai Gakkaishi 38 (1992) 107-113.

[14] Yamamoto H., Okuyama T., Yoshida M., Generation process of growth stresses in cell walls $\mathrm{V}$ : Model of tensile stress generation in gelatinous fibers, Mokuzai Gakkaishi 39 (1993) 118-125.

[15] Yamamoto H., Okuyama T., Yoshida M., Method of determining the mean microfibril angle of wood over a wide range by the improved Cave's method, Mokuzai Gakkaishi 39 (1993) 375-381.

[16] Yoshida M., Nakamura T., Yamamoto H., Okuyama T., Negative gravitropism and growth stress in $\mathrm{GA}_{3}$-treated branches of Prunus spachiana Kitamura $\mathrm{f}$. spachiana $\mathrm{cv}$. Plenanosea, J. Wood Sci. 45 (1999) 368-372. 